\title{
ENTRE O SILENCIAMENTO E A ACLAMAÇÃO, DISCURSOS SOBRE PAULO COELHO
}

\section{BETWEEN SILENCING AND ACCLAIM: DISCOURSES ABOUT PAULO COELHO}

\author{
Priscila Finger do Prado"
}

ResUMO: O presente trabalho objetiva, de maneira geral, analisar o discurso sobre Paulo Coelho, tendo em vista a forte adesão do público à sua obra e a indiferença/silêncio da crítica em relação ao seu papel na Literatura Brasileira. Partimos da hipótese de que havia um público cativo dos escritos de Paulo Coelho, o qual constitui um discurso de aclamação, bem como o grupo da crítica literária, para quem a escrita de Coelho não agrada, este grupo endossaria, segundo nossa hipótese, o discurso da indiferença ou do silêncio. Ao buscarmos os discursos sobre Paulo Coelho, verificamos que nossa hipótese, em parte, justifica-se, porém há outros sentidos envolvidos nesse discurso, o que o torna mais complexo que o esperado. Encontramos formações discursivas (FDs) relativas à indiferença e à aclamação, conforme nossa hipótese previa, mas também FDs relacionadas à repulsa e ao questionamento.

Palavras-chave: Paulo Coelho; discurso sobre; formações discursivas.

ABSTRACT: This paper aims to analyze the discourse about Paulo Coelho, considering the strong public support to his work and the indifference/ silence by the critics to this author's role in Brazilian Literature. Our hypothesis is that there was a captive audience to the writings of Paulo Coelho, who had a claiming discourse, while the literary critics, who do not really accept Coelho's writing, endorse the indifference's or silence's discourse, in accordance to our hypothesis.. As we seek the discourse about Paulo Coelho, we found out that this hypothesis is partly justified, but there are other meanings for this discourse, making it more complex than expected. We discovered discursive formations (FDs) about the indifference and claiming, as our hypothesis predicted, but also FDs related to disgust and questioning.

KEYwords: Paulo Coelho; discourse; discourse formation.

\footnotetext{
"Doutorado em Letras pela Universidade Federal do Paraná, professora no Departamento de Letras da Universidade Estadual do Centro-oeste - UNICENTRO.Email: priscilletras@yahoo.com.br
} 


\section{CONSIDERAÇÕES INICIAIS - O DISCURSO DE ACLAMAÇÃO SOBRE PAULO COELHO}

Paulo Coelho é um escritor brasileiro mundialmente conhecido, com inúmeros títulos e premiações. Quando se fala em Paulo Coelho, pode-se dizer que os números falam por si: ele é um dos escritores mais lidos do Brasil ${ }^{1}$ e do mundo, desde os anos 1980, quando do lançamento de O diário de um mago (1987) e O alquimista (1988); um de seus livros, O alquimista, está entre os dez mais lidos do mundo² é uma das personalidades atuais mais influentes da Internet (em pesquisa da Forbes de 2010 ele só "perdeu" para o cantor canadense Justin Bieber)³; e é membro da Academia Brasileira de Letras, desde 2002.

O curioso, no entanto, é exatamente o fato de os números precisarem falar por si. Quando pensamos o discurso de aclamação sobre Paulo Coelho, esse discurso vem de instituições que falam de números, mas não encontramos muitos defensores dispostos a "defendê-lo" em termos de qualidade e de literatura. Quem aclama Paulo Coelho? O público. Um público sem rosto, uma massa de leitores e seguidores que compram e leem seus livros e que, depois, seguem e postam suas declarações em redes sociais como Twitter e Facebook.

Ao procurarmos lugares em que o discurso de aclamação sobre Paulo Coelho aparece, tirando as pesquisas de leitores e de personalidades influentes, encontramos os sites do próprio escritor ${ }^{4}$ e seu espaço no site da Academia Brasileira de Letras, além, é claro, de seus perfis no Facebook ${ }^{5}$ e no Twitter ${ }^{6}$. Paulo Coelho precisa reforçar a aclamação que vem dos leitores, oferecendo números, nomes, trabalhos. Em seu site na ABL, por exemplo, destaca a crítica positiva de Umberto Eco a um de seus livros, como uma prova de seu mérito literário, já que Umberto Eco é um escritor e crítico reconhecido nos meios acadêmicos:

Autor de um trabalho polêmico, tem críticos apaixonados - a favor em contra. O escritor italiano Umberto Eco elogiou Veronika Decide Morrer na revista alemã Focus.

$[\ldots]$

\footnotetext{
${ }^{1}$ Segundo dados da pesquisa do Instituto Nacional do Livro, de 2008 e de 2011, quando o escritor alcançou, respectivamente, o $2^{\circ}$ e o $3^{\circ}$ lugar entre os mais lidos do Brasil. Disponível em: http://www.snel.org.br/wp-content/uploads/2012/08/pesquisa_habito_de_leitura_2008.pdf e http://prolivro.org.br/home/images/relatorios_boletins/3_ed_pesquisa_retratos_leitura_IPL.pdf. Acesso em 19/05/2015.

${ }^{2}$ Segundo compilação do escritor James Chapman, baseado em número de vendas, dos 10 livros mais lidos nos últimos 50anos, veiculada pela Biblioteca de São Paulo. Disponível em: http://bibliotecadesaopaulo.org.br/2013/04/30/10-livros-mais-lidos-no-mundo/. Acesso em 19/05/2015.

${ }^{3}$ Segundo dados da Forbes, veiculados pelo site de notícias G1, em 2010. Disponível em: http://g1.globo.com/tecnologia/ noticia/2010/12/justin-bieber-e-o-famoso-mais-influente-do-twitter.html. Acesso em 19/05/2015.

${ }^{4} \mathrm{http}: / /$ paulocoelhoblog.com/ e http://paulocoelhopt.blogspot.com.br/.

${ }^{5} \mathrm{https}: / /$ www.facebook.com/paulocoelho.

${ }^{6} \mathrm{https} / / /$ twitter.com/paulocoelho.
} 
Tem sido elogiado por pessoas tão diferentes como o Prêmio Nobel de Literatura Kenzaburo Oe, o prêmio Nobel da Paz Shimon Peres, a cantora Madonna e Julia Roberts, que o consideram seu livro favorito7.

O escritor também dá nomes a alguns de seus leitores, principalmente aqueles que são famosos e que "assumiram" gostar de seus livros, como Shimon Peres, Madonna e Julia Roberts. Contudo, sua descrição no site da ABL confirma uma posição polêmica que encontraremos em relação ao escritor - a favor e contra, posição que vai aparecer em nossa pesquisa do discurso sobre Paulo Coelho. Partimos dos lugares da aclamação (do público) e do silenciamento (da crítica), porém, o estudo do discurso sobre Paulo Coelho nos mostrou que há outros lugares discursivos aí colocados, os quais veremos na sequência deste trabalho.

\section{SOBRE DISCURSOS E LUGARES - O APORTE TEÓRICO DA ANÁLISE DE DISCURSO}

A concepção de discurso que baseia nosso trabalho é a discursiva, para a qual o discurso é visto como palavra em movimento, como prática de linguagem. Para Orlandi, em seu Análise de discurso: princípios e procedimentos (2001), o discurso se dá na relação de mediação que há entre o homem e a realidade natural e social que o cerca. Essa ideia de palavra em movimento é retomada de Pêcheux, quando este afirma que:

o sentido de uma palavra, de uma expressão, de uma proposição etc., não existe "em si mesmo" (isto é, em sua relação transparente com a literalidade do significante), mas, ao contrário, é determinado pelas posições ideológicas que estão em jogo no processo sócio-histórico no qual as palavras, expressões e proposições são produzidas (isto é, reproduzidas). (PECHEUX, 2014, p.146.).

Essa relação entre o que se diz e quem o diz está estreitamente ligada à questão das formações ideológicas. Quando um sujeito fala, ele não fala "neutramente", ele se inscreve dentro de uma formação ideológica. Para a $\mathrm{AD}$, "aquilo que, numa formação ideológica dada numa conjuntura dada, determinada pelo estado da luta de classes, determina o que pode e deve ser dito" (PECHEUX, 2014, p. 147) ganha o nome de formação discursiva (FD). Dessa forma, o sentido das palavras que proferimos advém da formação discursiva em que nos inscrevemos, mesmo que isso não se dê de forma consciente.

Pensar o discurso sobre Paulo Coelho é, pois, pensar os lugares discursivos e as formações discursivas que possibilitam os dizeres. Importante destacar, para a perspectiva de nosso estudo, que se há alguma contradição na formação de um discurso sobre alguém ou

${ }^{7}$ Disponível em: http://www.academia.org.br/academicos/paulo-coelho/biografia. Acesso em novembro de 2015. 
algo, isto se dá porque há também algum tipo de contradição nas relações sociais e ideológicas de base desse discurso. Para Pêcheux (1997, p. 93), "as contradições ideológicas que se desenvolvem através da unidade da língua são constituídas pelas relações contraditórias que mantêm, necessariamente, entre si os 'processos discursivos', na medida em que se inscrevem em relações ideológicas de classes". Nessa perspectiva, o discurso de não-aceitação do lugar literário de Paulo Coelho, por exemplo, seria o índice de uma ideologia que vê a prática literária como elitizada, prática de poucos, dirigida a um público seleto. Por esse viés, o próprio entendimento e aceitação por parte do grande público representariam uma "falta" da obra e/ ou do autor em relação a aspectos eruditos e literários.

O que se deduz, a partir de leituras primeiras é que a crítica a Paulo Coelho, o discurso sobre Paulo Coelho aparece textualizado em artigos críticos sobre obras lançadas e artigos mais informais da internet, muito embora não vejamos grandes posicionamentos por parte da academia (lato sensu). Em verdade, tem-se a impressão de que os representantes das universidades e da própria $\mathrm{ABL}$ não se sentem muito à vontade com a presença de Coelho entre eles, mas, como não seria ético criticar um colega, eles colocam seus discursos na ordem do silêncio.

Quanto a ideia de discurso sobre, buscamos referencial teórico nas leituras de Mariani (1999) e Venturini (2008). Faz-se necessário também aqui explicar como utilizamos essa expressão, visto que o uso da preposição $\mathrm{DE}$ ou da preposição SOBRE modificam a perspectiva do sujeito em relação ao discurso. Para Venturini (2008), as modalidades de "discurso de" e de "discurso sobre" seriam, ambas, pertencentes ao lugar da rememoração. Contudo, o "discurso sobre" estaria estabelecido como interdiscurso (pré-construído), ao passo que o "discurso de" teria o papel de discurso fundante, estando fortemente ligado ao primeiro: "o discurso sobre se constitui pelo discurso de, que funciona como a memória que o constitui e como o discurso fundante que retorna e o ancora". (VENTURINI, 2008, p. 65).

Sabemos que as definições dadas por Venturini (2008) se baseiam em pesquisa de objeto de estudos específico, de modo que temos que utilizá-las com cuidado, buscando uma forma de adaptá-las ao nosso objeto, principalmente porque o discurso estudado pela autora, sobre Érico Veríssimo, constitui-se pelo viés da comemoração, ou seja, mais próximo à exaltação, ao passo que o discurso sobre Paulo Coelho apresenta outros efeitos de sentido. Mesmo assim, a busca pela análise de um "discurso de" ou de um "discurso sobre" possibilita efeitos de sentido diversos. Para o que aqui nos interessa, o discurso sobre, Mariani, na leitura de Venturini (2008, p. 66), defende que "o efeito imediato do discurso sobre é tornar objeto o nome ou o evento sobre o qual fala o sujeito no discurso". Falar sobre Paulo Coelho é torná-lo objeto; portanto, ao buscarmos os sentidos que alcançam o discurso sobre Paulo Coelho, pensamos em textos que fazem do autor objeto de suas reflexões. O discurso sobre Paulo Coelho estaria, pois, numa posição de interdiscurso, preso a determinadas formações discursivas.

Outro aspecto merece ser destacado, a fim de que possamos pensar o discurso sobre Paulo Coelho: o silêncio. Dentro dos estudos discursivos, Eni Orlandi (1995) é uma das autoras 
que pesquisa o lugar do silêncio no campo discursivo. Para a autora, o silêncio pode ser visto como significativo em dois casos, quando funda/possibilita o dizer ("silêncio fundante") e quando impossibilita o dizer ("silêncio como política de censura"). O primeiro silêncio seria o da ordem das palavras, o espaço significante onde o dizer pode se inscrever. Nesse sentido, como declara Orlandi (1995), o silêncio seria "falta", e a língua, "excesso", de modo que o discurso seria uma forma de conter os sentidos que no silêncio se apresentam como possíveis. $O$ segundo silêncio seria aquele que impossibilita o dizer, em circunstâncias dadas, sejam elas políticas ou culturais. Esse segundo tipo é que nos permite pensar nos discursos sobre "aclamação" e "silêncio", que surgiu como nossa primeira hipótese para a análise do discurso sobre Paulo Coelho. Daí a importância de pensarmos quem aclama e quem silencia, que formações discursivas possibilitam esses dizeres.

Assim, mais do que os discursos sobre Paulo Coelho que iremos estudar, interessa-nos os lugares discursivos de onde são enunciados. Que formações discursivas estão envolvidas nesse discurso, a partir de nossa hipótese, que leva em conta os lugares do silêncio e da aclamação? Haverá outras formações discursivas que baseiam discursos sobre Paulo Coelho? Buscaremos refletir sobre essas questões, partindo de discursos sobre o autor.

\section{UM SILÊNCIO BEM INTENCIONADO: PAULO COELHO E AS HISTÓRIAS LITERÁRIAS}

Muito se fala sobre a crítica ferrenha que é dedicada a destituir Paulo Coelho do lugar literário, mas, em verdade, não se encontram tantos textos de crítica à sua obra como o esperado. Ao pesquisar seu nome junto às grandes histórias da literatura brasileira que abarcam o período contemporâneo, verificamos um absoluto silêncio. Das obras que buscam compilar estudos sobre diferentes momentos da literatura brasileira, dando-lhes uma noção de conjunto, e que chegam até a produção contemporânea, podemos destacar a Historia concisa da Literatura Brasileira (2006), de Alfredo Bosi, e a Literatura Brasileira através dos textos (2004), de Massaud Moisés. Nestas, o nome Paulo Coelho sequer é mencionado, embora a posse do autor na Academia Brasileira de Letras tenha ocorrido em 2002, ou seja, haveria tempo para os estudiosos, se julgassem necessário, mencionarem algum ponto sobre a obra de Coelho e sua aclamação pelos leitores. O que significa termos um escritor brasileiro contemporâneo ignorado pelas histórias da Literatura? Que sentidos trazem esse silêncio? Se o discurso sobre é aquele que transforma um nome em objeto, o que significa silenciá-lo?

Esse silenciamento nos traz à mente a concepção elaborada por Orlandi (2005), segundo a qual haveria um tipo de silencio que funcionaria como um censor do dizer, de modo que, em circunstâncias dadas, dependendo da formação ideológica dos sujeitos, alguns dizeres seriam "proibidos". Nesse caso, falar bem ou mal de um escritor contemporâneo, reconhecido mundialmente e aclamado por um largo público, exigiria uma responsabilidade de um autor 
de história literária que talvez ele não quisesse exercer. Contudo, não mencionar seu nome em meio à produção literária nacional, tendo em vista, principalmente o lugar de acadêmico da ABL de Paulo Coelho, implica também uma tomada de posição.

Uma história da literatura visa enumerar uma seleção de autores que fazem parte de um fazer literário memorável. O discurso sobre, numa história da literatura, é o preponderante, autores são tornados objeto com o intuito de figurarem entre os autores que fazem parte da produção literária de um país. E o silêncio, nessa perspectiva, significa, no mínimo, que o autor (ainda?) não conseguiu, com sua produção literária, fazer-se merecedor de constar entre o rol dos autores destacados da nação.

No caso da Literatura Brasileira, considerando as histórias da literatura cujas edições abarcam a produção contemporânea, Paulo Coelho é silêncio. Dentre as possibilidades de autores que se tornaram objeto com o "discurso sobre", o autor não consta. Acumular leitores, ser membro da $A B L$, ser referência no mundo virtual, nenhuma dessas ações, por si só, são capazes de lhe garantir um lugar entre a história da literatura nacional por ora. E esse silenciamento significa uma crítica. Uma crítica da Crítica especializada, acadêmica, avalizada. E como seriam os discursos sobre o autor que circulam na internet? Isso é o que nos propomos analisar no subtítulo a seguir.

\section{O AVESSO DA ACLAMAÇÃO: OS DISCURSOS SOBRE PAULO COELHO NA INTERNET (QUESTIONAMENTO E REPULSA)}

Dentre os artigos de opinião ou de análise encontrados, podemos citar "A força da imaginação ou o blefe do jogador? Entretenimento e espiritualidade na era da globalização", de Martin Cezar Feijó, publicado na Revista da Faculdade de Comunicação da FAAP, no $2^{\circ}$ semestre de 2002. Este artigo busca analisar a obra de Coelho de uma perspectiva da recepção, identificando na sociedade contemporânea uma carência para a qual Coelho tem a "cura". Para Feijó, é importante que nos concentremos no momento cultural e político que vivemos, esta será a chave para entender o sucesso do escritor mago.

O sucesso internacional foi rápido e indiscutível. Realmente atribuir isto a apenas o resultado de uma estratégia de marketing é recusar um princípio caro às regras publicitárias: o produto que não convence, não vinga. Também supor que sociedades secretas ou lojas maçônicas tenham sido responsáveis pela difusão de uma obra regular e coerente não ajuda muito a compreender o fenômeno, além de alimentar exatamente as bases teóricas que o sustenta. A razão principal do sucesso de Paulo Coelho está no momento cultural e político que vivemos. (FEIJÓ, 2002, p. 3). 
Feijó também destaca que, para além das estratégias de marketing, que colocam os livros de Coelho como produtos, e do esoterismo que perpassa os livros e a vida do autor, há uma recepção favorável, há um público que se identifica com sua obra, por isso esse fenômeno deve ser analisado, para entendermos mais sobre a cultura e a sociedade contemporâneas. É importante lembrar que o artigo propõe o discurso sobre Paulo Coelho como um discurso sobre um produto que vende bem, buscando razões para essa boa aceitação. É um viés publicitário, pois, e não literário.

Outro artigo que cabe ser citado é o que aparece na revista Língua Portuguesa, edição 10, da Editora Segmento, com o título de "Paulo Coelho: afinal, ele escreve bem? A marca do Coelho", de autoria de Ronaldo Abanese. Este se utiliza da citação de pessoas que fizeram pesquisas sobre Coelho para dar pinceladas sobre o problema apresentado no título. Em sua leitura da obra de Mário Maestri, Por que Paulo Coelho teve sucesso (2004), Abanese coloca a obra de Coelho como Para-literatura, por ter estrutura e elementos gerais da ficção, sem registrar conteúdos essenciais dos fenômenos relatados. Segundo a leitura de Maestri por Abanese, o estilo de Coelho tem as seguintes características: eficiência jornalística, recursos dramáticos, atualização do exoterismo e narrativa "quietista". Duas coisas aqui devem ser reparadas, o veículo em que o artigo surge, uma revista sobre língua portuguesa e o título escolhido. Esse título destaca uma das críticas que se faz ao autor, a despeito do sucesso de vendas, uma escrita ruim. Para uma revista de língua portuguesa, o argumento vem de uma tradição retórica, em que obras literárias devem ser bem escritas, de modo que obras literárias fora da norma padrão não seriam adequadas. Mas, novamente, a perspectiva não é diretamente a da literatura.

Ao buscarmos a perspectiva do autor que embasou o artigo de Abanese, no texto "O Bruxo veste o fardão”, de Mário Maestri, pudemos perceber mais detalhes sobre a análise que ele faz da obra coelhiana. Apesar de posicionar os livros de Coelho fora do âmbito do que considera literário propriamente, Maestri defende o estudo do autor pela academia, visto que Paulo Coelho é um fenômeno de vendas, e esse dado poderia nos fornecer informações importantes sobre a sociedade que recebe sua obra. Novamente, o literário não é o reiterado no discurso sobre Paulo Coelho, o discurso sobre o autor é um discurso sobre o fenômeno de vendas e sua importância cultural.

A perspectiva apresentada pelos textos de Feijó e Maestri (e de Abanese também, apesar de seus argumentos advirem da leitura dos textos de Maestri) constituiria a "perspectiva branda" de análise da obra de Paulo Coelho. Tanto Feijó quanto Maestri fazem parte do universo acadêmico e se colocam dentro de uma formação discursiva, a partir da qual tudo o que interessa a sociedade se faz interessante para o estudo universitário, que deveria buscar a aproximação entre a universidade e a sociedade na qual se insere, contemporaneamente. Fazem parte dessa FD os discursos sobre Paulo Coelho que buscam analisar sua obra como literatura de massa ou sob o viés da Estética da Recepção. Em ambos os casos, o sujeito se omite de qualificar o objeto de pesquisa quanto a ser ou não literário, conforme o que propõe 
a Tradição Literária, mas entende-se que a própria fuga desse recorte já seja uma tomada de partido. O discurso sobre Paulo Coelho pode acontecer, no universo acadêmico, contanto que seja enfocado somente o fenômeno de vendas e de leitores.

Ainda nos textos que circulam na internet, podemos encontrar outra posição, defendida principalmente por jornalistas e blogueiros, cujos textos aparecem em jornais, revistas e blogues. Desse ponto de vista, o "legal" é criticar Paulo Coelho, dizer que qualidade não é quantidade, que sua obra é pura auto-ajuda. Estes autores se colocam como defensores da Grande Literatura e, com isso, apresentam-se como "superiores", como cults.

Um dos representantes desse grupo é o texto publicado na Folha de São Paulo, em abril de 2014, de autoria de Marcelo Dantas, "Não há literatura em novo romance de Paulo Coelho". O texto trata sobre o novo romance de Paulo Coelho, Adultério, o qual, para Dantas, segue o modelo dos livros anteriores:

Literatura não há em "Adultério". Estamos diante de um produto. Apenas isso. A narrativa é linear e monocórdia. Ao estilo, falta inventividade.

As personagens não chegam a existir. A protagonista sofre dessa insuficiência ontológica que costuma acometer as heroínas de Paulo Coelho. (DANTAS, 2014).

É interessante destacar aqui que, quando o crítico nega o literário em Paulo Coelho, seu argumento é o livro como produto. A questão da sociedade de consumo é, pois, destacada. Esse consumo, o de massa, é o do grande público, com o que fica subentendido que a Literatura não é um produto vendável, ou, se é, o é para poucos. A massa é um fator que desqualifica o produto literário.

A questão do consumo é retomada em outro momento do texto de Dantas. Aqui também percebemos novo argumento para desqualificar a obra de Coelho como literária: a comparação com "verdadeiras" obras da Literatura:

Um conselho? Poupe o seu dinheiro. Se quiser um livro, lembre-se Hawthorne, Flaubert e Tolstói escreveram obras-primas sobre o tema; Joyce mergulhou na mente adúltera de Molly Bloom; e o maior romance da língua portuguesa busca convencer-nos da infidelidade de uma jovem com "olhos de cigana oblíqua e dissimulada".

Se a obra de Paulo Coelho não é literatura, é preciso destacar aquelas que são, e nada mais convincente do que nomes autorizados como Tolstói ou Joyce. Note que a obra de Coelho não é comparada a autores contemporâneos, mas a escritores que já fazem parte do cânone. $O$ discurso sobre Paulo Coelho é um discurso sobre o que não é literário. O discurso de Dantas é sustentado pelo discurso do cânone, de que só é literatura o que consta no rol das obras eleitas como literatura, de preferência, os "clássicos". E assim, tudo o que disser será avalizado. 
Esses dizeres sobre o pano de fundo de um discurso autorizado constitui uma das formações discursivas sobre a Literatura. A partir desta $\mathrm{FD}$, o sujeito inscrito só tem argumentos pró e contra o que já está avaliado pela crítica. De certa forma, esse é um lugar cômodo e seguro: os argumentos estão prontos e é difícil refutá-los.

No segundo artigo selecionado, "Paulo Coelho não é literatura", de Jonatan Rafael da Silva, publicado em seu blog pessoal, percebemos alguns movimentos discursivos semelhantes aos do artigo publicado por Marcelo Dantas na Folha de São Paulo. A tese é a produção de Paulo Coelho não é literatura, e os argumentos são enunciados a seguir. O primeiro argumento é o de que quantidade não é qualidade e, com ele, a ideia de que muitos bons escritores venderam pouco, ao que Silva cita Herman Melville como exemplo. Aliás, citar Melville faz parte do segundo movimento discursivo do texto contra Coelho: as comparações com grandes nomes da Literatura. Não foi o que fez Marcelo Dantas no artigo para a Folha? Então, Silva lança mão do argumento do esoterismo como desqualificador da obra de Coelho:

A falta de qualidade e, principalmente, características literárias sólidas estão entre os principais fatores que não coloquem [sic] o Mago no grande circuito da literatura. As expressões "bom combate", "lenda pessoal", a teria [sic] na qual tudo conspira a seu favor, e frases como "Nunca desista dos seus sonhos" não passam de um grande engodo para enredar os fracos - pessoas que não estão acostumadas com a leitura de Wilde, Woolf, Joyce, Machado, Borges et ali. (SILVA, s.d.)

É interessante destacar aqui que, quando se deprecia um autor como Coelho, o autor se incumbe de um lugar autorizado: quem é acostumado a ler boa literatura como Woolf ou Joyce não se contenta com má literatura. E o que fica implícito aqui? Que quem critica Coelho pertence a um grupo seleto, autorizado, avalizado pelo discurso da Tradição. Nesse caso, tanto o texto de Dantas quanto o de Silva aparecem junto à Formação discursiva da "repulsa", baseada na Tradição literária como principal argumento. O oposto a isso seria a permissividade dos estudos culturais, nos quais impera o "vale-tudo" que não deve ser admitido por quem realmente entende de Literatura, e aí teremos a eterna querela entre os que defendem somente as obras canônicas e outras perspectivas de estudo da Literatura, como os estudos culturais, que são vistas com preconceito pelos primeiros.

Para além do "silenciamento" (das história da literatura) e da "aclamação" (do público leitor), que seriam nossa hipótese de formações discursivas de análise para o discurso sobre Paulo Coelho, encontramos um meio-termo, que busca analisar o lugar de Paulo Coelho como literatura de massa, um produto vendável, porque aceito por um grande grupo de leitores. Mais que isso, essa vertente discursiva aponta Paulo Coelho como um fenômeno que DEVE ser estudado. Essa perspectiva vem ao encontro dos estudos acadêmicos sobre o autor e sua obra. A essa formação discursiva atribuímos a denominação “questionamento", para fins de análise. 
Ainda nesse meio-termo entre o silenciamento e a aclamação, encontramos um espaço de crítica ferrenha à obra e à figura de Coelho. Este espaço de crítica vem principalmente de uma perspectiva não acadêmica, em textos de jornais, revistas e blogs, mas avalizadas pela Tradição Literária (cânone). Denominamos essa formação discursiva como de "repulsa", para fins de análise, sendo que um modo de interpretá-la é vê-la como uma forma de pertencer a um lugar privilegiado de discurso: criticar Paulo Coelho nos deixa mais cults! Assim, ao estudarmos o discurso sobre Paulo Coelho, problemático ou "polêmico" no próprio dizer do autor sobre sua obra, percebemos a presença de quatro formações discursivas: a da aclamação, a do silenciamento, a da repulsa e a do questionamento. Os sujeitos que as enunciam em seus discursos, não o fazem gratuitamente, e sim por estarem imbuídos de determinadas formações ideológicas. Aclamar Paulo Coelho é esquecer (ou ignorar) conceitos da Tradição Literária. Silenciar Paulo Coelho é esquecer (ou ignorar) que todo fenômeno social merece estudo e respeito (principalmente por parte da academia). Repudiar Paulo Coelho é esquecer que existem outros referentes além do cânone, e que há milhões de envolvidos nesse processo. Questionar Paulo Coelho é, nosso ver, um discurso que reconhece seus esquecimentos, que buscar estudar o que é caro à sociedade, ainda que não exista neutralidade.

\section{CONSIDERAÇõES FINAIS - O DISCURSO SOBRE PAULO COELHO}

Nesse momento, cabe retomar a perspectiva discursiva para tentar explicar os dados encontrados (embora já o tenhamos feito no decorrer sem explicações teóricas mais extensas).

O discurso é palavra em movimento, prática de linguagem. E, nesse sentido, Paulo Coelho é também um objeto de linguagem, na medida em que se torna objeto de discursos. O discurso sobre Paulo Coelho é, pois, a prática de linguagem que o transforma em linguagem, passível de todo o tipo de posicionamento, dependendo de quem fala sobre ele e de que lugar se fala sobre ele. E essa relação de sujeitos e discurso, bem como de lugares discursivos é matéria de interesse da Análise de Discurso, segundo a qual, toda vez que se fala inscreve-se numa formação ideológica dada, visto que o dizer é histórico e os discursos se repetem, porque as coisas de que se fala, de uma forma ou de outra, também se repetem. Essa relação entre formações ideológicas e a historicidade do dizer nos permite a ideia de formações discursivas, "aquilo que, numa formação ideológica dada numa conjuntura dada, determinada pelo estado da luta de classes, determina o que pode e deve ser dito". (PECHEUX, 2014, p. 147). O que falamos ganha sentido, então, de acordo com a formação discursiva em que nos inscrevemos, mesmo que isso não se dê de forma consciente.

Assim, quando dizemos que há um silenciamento sobre Paulo Coelho e sua obra em obras de referência da literatura, especificamente os manuais de historiografia literária brasileira, temos sentidos transitando. Isso nos permite interpretar que, dentre o rol dos autores com produção literária digna de menção, o autor não se encaixa. Contudo, tendo em vista a 
formação discursiva da aclamação, com o argumento da quantidade de leitores, e mais, tendo em vista a posse do escritor na $\mathrm{ABL}$, temos uma situação discursiva diferenciada. Essa situação, é claro, é-nos "decifrada", se levamos em conta quem são esses que clamam. Quem são eles? Eles são "a massa", ou melhor, todos aqueles que não fazem parte da minoria especializada que silencia sobre Paulo Coelho, a qual constitui a formação discursiva do silenciamento. São duas formações discursivas diferentes, são sujeitos diferentes que as constituem.

Porém, com o decorrer de nossa análise, verificamos que há outros discursos sobre Paulo Coelho. Há os que o repudiam fervorosamente. É a formação discursiva da repulsa. Esses, podemos dizer, são parte (ou gostariam de fazer parte) do grupo que silencia, dessa minoria especializada que define o que é e o que não é literatura. Encontramos esse discurso em jornais e revistas de circulação nacional e em blogs pessoais. $\mathrm{O}$ argumento principal é falar contra Paulo Coelho, contra seus leitores, visto que o que ele escreve carece de qualidade literária. E como se comprova isso? Comparando com grandes nomes da literatura, os escritores canônicos. O que baseia essa formação discursiva, se não a ideia de literatura como prática elitista e elitizada, segundo a qual o que a "massa" gosta não pode ser admitido como literário? Mas resta a questão: a "má" literatura não seria ainda literatura?

Há também os que falam sobre Paulo Coelho enquanto fenômeno de vendas e de leitura e que buscam razões para esse fenômeno. Nestes, ainda que haja críticas em relação ao status literário, mesmo que sutis, prevalece a reflexão, o "espírito" acadêmico. Esse é o discurso da academia, no sentido lato, de universidade. São professores e pesquisadores, para quem tudo o que se destaca no seio da cultura merece reflexão. Temos aqui outra formação discursiva, a do questionamento. E como respostas para a razão do fenômeno Paulo Coelho, destaca-se o cenário mundial com o individualismo e o consumismo, que massificam as pessoas, as quais devem buscar "consolo", entre outros meios, também na literatura. A resposta é, portanto, o leitor. O que acaba fazendo um elo entre essa formação discursiva do questionamento e a FD da aclamação. Uma como "problema", outra como "análise". Da mesma forma, pode-se unir a FD do silenciamento à FD do repúdio, pois que os ampara uma visão dicotômica da linguagem e dos que a utilizam, destacando a ideia da luta de classes como algo que permeia os discursos e, nesse caso, busca a manutenção da ordem social, sem possibilidade de intercalação entre sujeitos e discursos. O que isso quer dizer? Isso quer dizer que quem lê Paulo Coelho está num lugar desprivilegiado de saber e de leitura. Isso quer dizer que quem não lê Paulo Coelho pode fazer parte desse lugar privilegiado de leitura. Mas, e principalmente, isso quer dizer que eu não posso, enquanto sujeito do grupo privilegiado, admitir que leio e/ou que gosto de Paulo Coelho, o que também impossibilita que eu, enquanto leitora de Paulo Coelho, possa fazer parte do grupo privilegiado de saber e leitura.

O estudo que nos propomos nos mostrou mais do que simples diferenças de opinião. Mostrou-nos que a estrutura social se reflete mais do que pensamos nas escolhas de linguagem, assim como nos mecanismos de escolha de leitura. Discursar sobre algo é assumir uma 
formação ideológica e discursiva. Criticar um autor que vende pode ser uma forma de perpetuar a luta de classes, no sentido de nos impossibilitar entrecruzamentos discursivos e ideológicos. Se é bom ou não ler Paulo Coelho, não podemos dizer aqui, nem era esse nosso objetivo, mas ao dizer se é bom ou não ler Paulo Coelho, estamos assumindo uma formação discursiva que nos antecede. E desfazer a novidade do dizer é uma das tarefas da Análise do Discurso.

\section{REFERÊNCIAS}

ABANESE, R. Paulo Coelho: afinal, ele escreve bem? A marca do Coelho. In: Revista Língua Portuguesa, edição 10, da Editora Segmento, 2006. Disponível em: https://professorronaldo. files.wordpress.com/2013/03/a-marca-do-coelho.pdf. Acesso em: 06/02/2020.

BIOGRAFIA DE PAULO COELHO. Disponível em: http://www.academia.org.br/abl/cgi/cgilua. exe/sys/start.htm?infoid=322\&sid=233. Acesso em: 20/08/2014.

BOSI, Alfredo. Historia concisa da Literatura Brasileira. São Paulo, Cultrix, 2006.

DANTAS, Marcelo. Crítica: Não há literatura em novo livro de Paulo Coelho. Folha de São Paulo, 25/08/2014.

FEIJÓ, M. C. A força da imaginação ou o blefe do jogador? Entretenimento e espiritualidade na era da globalização. FACOM. Revista da Faculdade de Comunicação da FAAP. São Paulo: v. 10, p. 51-57, 2002.

MAESTRI, M. Por que Paulo Coelho teve sucesso. Porto Alegre: AGE, 1999.

MARIANI, B. Discurso e instituição: a imprensa. Revista Rua. v.5. Campinas, SP: UNICAMP, 2003. MOISÉS, M. Literatura Brasileira através dos textos. Cultrix, 2004.

ORLANDI, E. P. Análise de Discurso: princípios \& procedimentos. 8. ed. Campinas: Pontes, 2009. ORLANDI, E. P. As formas do silêncio: no movimento dos sentidos. 3. ed. Campinas: Ed. Unicamp, 1995.

PÊCHEUX, M. Semântica e discurso: uma crítica à afirmação do óbvio. (tradução de Eni Orlandi [et al.]). Campinas/SP: Editora da UNICAMP, 1997.

SILVA, J. R. da. Paulo Coelho não é literatura. In. Nada de meias palavras: aqui gosto se discute (blog). Disponível em: https://nadademeiaspalavras.wordpress.com/2013/01/22/220-paulocoelho-nao-e-literatura/ Acesso em: 27/08/2014.

VENTURINI, M. C. Rememoração/comemoração: prática discursiva de constituição de um imaginário urbano. Tese (Doutorado em Letras) UFSM, 2008. 